\title{
Photography as a Research Method with Learners in Compulsory Education: A Research Review
}

\author{
Helen HANNA \\ Institute of International and Comparative Education, East China \\ Normal University, Shanghai, China \\ drhelenhanna@outlook.com
}

\begin{abstract}
This article offers a review of thirty-one research articles from 2001-2019 on the use of photography as a research method with learners in compulsory education. Understood within the scope of 'visual', 'participatory' and 'arts-based' research methods, many scholars have linked the increased use of the photographic method to greater awareness of the rights of the child and changing understandings of children as full 'human beings' with agency rather than simply vulnerable 'human becomings'. Nevertheless, photography is still a relatively under-utilised approach in research with learners in school-based compulsory education and its use is not widespread globally. Against the background of the history of visual and photographic methods in general and in education in particular, this article highlights two key themes in the empirical research literature: why the photographic method is used (dealing with representation, participation and emancipation); and how the photographic method and the photos themselves are used (pre-generated and participant-generated photographs). It closes with a reflection on what may be holding back its expansion, including key ethical concerns, and a proposal for encouraging its use in education.
\end{abstract}

\section{Keywords}

photography - visual method - research method - school - student - research review 
It has been argued that the research methods that social researchers use should be applied creatively so that they can be made 'fit for purpose' (Kara, 2015). With this responsibility in mind, a plethora of visual (Banks, 2001; Pink, 2001; Rose, 2001), arts-based (Leavy, 2008; Knowles \& Cole, 2008) and participatory (Reason \& Bradbury, 2008; Chevalier \& Buckles, 2013) methods have been evolving, particularly over the last four decades. Scholars have linked this development to a number of shifts, two of which can be related to children and young people and school-based research. The first shift is in understandings of children and young people that came around the time of the United Nations Convention on the Rights of the Child in 1989, and particularly the legal obligation for the 'best interests' of children to be taken into consideration, and the views of children to be taken into account on anything that affects them (Lundy, 2007; Lansdowne, 2011; Hanna, 2019). The second shift relates to the movement within the sociology of childhood that began to more vocally advocate the appreciation of different childhoods where children were increasingly seen not as a vulnerable collective who needed protection, but as individuals holding agency to act on their world and the capacity for independent thought: as fully-fledged 'human beings' rather than simply 'human becomings' (James \& James, 2004). These two shifts, it may be argued, lead to the conclusion that children and young people should be allowed to 'represent' themselves to the world (Prout, 2001). Therefore, it is sometimes argued that these, more creative methods hold the potential to offer a more holistic, inclusive and flexible approach to exploring social realities - and a more enjoyable and engaging research experience - particularly with children and young people as research participants (Thomson, 2008; Stirling \& Yamada-Rice, 2015).

One method that may be included within this shifting methodological landscape is photography. Used widely within anthropology from the late 19th century, it now holds a firm place in 21st century research methods literature (Banks, 2001). However, while photography has been used fairly frequently as a method in some other fields, as will become clear from the limited number of research articles that were available for this review, it is still a relatively underutilised approach in school-based compulsory education. This is despite the enduring and perhaps growing salience of visual culture due to the widespread use of social media among younger people in particular (Woodfield, 2014), a conundrum that this Special Issue seeks to take some steps towards addressing.

Against such a background, this article offers a review of thirty-one empirical research articles from the past eighteen years (2001-2019) on the use of 
photography as a research method with learners in compulsory education. It considers the development of visual and photographic methods in research in general and within educational research in particular. Then it presents the scope of this research review and the search strategy employed to find the articles included within it. Following this, it moves on to the two main themes that emerged from reviewing the research papers, namely: why the photographic method is used (dealing with the key motivations of representation, participation and emancipation); and how the photographic method and the photographs themselves are used (distinguishing between pre-generated and participant-generated photographs). It closes with a reflection on what may be holding back its expansion, including key ethical concerns, and a proposal for encouraging its use in education.

\section{$2 \quad$ Visual and Photographic Methods in Social Research}

Photography has variously been described as a 'visual', 'visual ethnographic', 'participatory' and 'arts-based' method, depending on how and with whom it is used. Photography first began to be used as a research method within anthropology and ethnography in the early 2oth century, when photographic equipment became accessible to researchers (Banks, 2001). In this sense the camera was usually used by the researcher-photographer as a way of capturing an aspect of a community: as 'photo-documentation' (Rose, 2001). Since then, the method has seen various evolutions, and particularly a significant movement towards being used as a way of involving participants in the research process itself, either through using 'found', researcher-produced or pre-existing photographs, or through participants producing photographs themselves.

Key scholars who have been active in the field of visual ethnography over the past two decades include Sarah Pink (2001), Gillian Rose (2001), and Marcus Banks (2001), who have explored the various debates and dilemmas that have arisen as the method has evolved. For example, in her monograph, Pink (2001) proposes that images are everywhere, 'inextricably interwoven with our personal identities, narratives, lifestyle, cultures and societies, as well as with definitions of history, space and truth.' (p. 17) She therefore concludes that visual ethnographic researchers must appreciate the interlinkage between the oral/aural and the visual, for ' $[\mathrm{j}]$ ust as images inspire conversations, conversations may invoke images...images are as inevitable as sounds, words or any other aspect of culture or society.' (p. 17) Rose (2001) highlights issues of representation in terms of the extent to which an image can represent an object, person, place, time or concept; related to this is the issue of 'audiencing' which 
can influence how a particular image is understood and interpreted, a huge challenge for researchers in any qualitative research but perhaps particularly in visual research. Banks (2001) proposes that visual research is a 'collaborative project between image maker and image subjects' and so, social researchers '[can]not pretend that they can somehow transcend their humanity and stand outside, merely observing'. (p. 112) There have also been notable contributions from Claudia Mitchell (2011) in her monograph Doing Visual Research and Pat Thomson's (2008) edited collection Doing Visual Research with Children and Young People. Many of the key debates explored in these monographs and volumes emerge also from the articles selected for this research review and will be returned to later.

In terms of photography in particular, it may be said that its use as a research method has expanded significantly, being used in very different ways to cover different topics and work with different groups of people, to serve different ends and to address or challenge some ethical issues. There have been notable edited collections published from the 1960s onward, such as John Collier's collaboration with Malcolm Collier in their book Visual Anthropology: Photography as a Research Method. (Collier \& Collier, 1967) One of the bestknown pioneers in this area has been Caroline Wang (along with Burris in the early days) who from 1997 began to publish on 'photo-voice' or 'participatory photography' in health and community contexts (see, for example, Wang, 1999). 'Photo-voice' is a method that involves participants documenting their experiences through photography and then discussing them, with a view to bringing about criticality, empowerment and change, all within a participantled environment. (Wang, 1999) It is an approach that has been used quite extensively within community settings, where a research participant will often have the use of a disposable camera and will therefore be able to take photographs within their daily lives. In this way, Wang has inspired a whole generation of researchers who wish to use a participatory approach to research, where participant-researchers are fully informed and leading and moulding the research in some way. It is also strongly associated with 'photo-elicitation' (Collier \& Collier, 1986; Harper, 2002) whereby participants describe the photographs and sometimes write short inscriptions for them, that may or may not be shared publicly. However, 'found' or researcher-generated photographs have also been used as a way of sparking discussion or debate or tapping into a memory. Both of these approaches will feature in the themes of this research review below.

What may be apparent so far is that the best-known scholars in photography as a research method appear to be located outside of the field of education. While its use within social science research in general may be traced to the 1960s, as Kaplan, Lewis and Mumba (2007) noted, it is very difficult to trace 
the origin of the photographic method within compulsory education; in 1998 Wetton and McWhirter wrote on health education, in the same year, Prosser (1998) discussed the fact that text is normally more highly valued than images in educational research, and the earliest research paper that could be found for inclusion in this review was from 2001, which investigated sociability and cooperation among 4-5 year olds in England, using researcher-generated photographs (Broadhead, 2001). There are some notable, more recent contributions specific to education that will interest the reader. There is extensive treatment of photographic methods in Miles and Howes' (2015) edited collection Photography in Educational Research: Critical Reflections from Diverse Contexts. There is also the Wylie Handbook of Ethnography in Education from 2018 which includes a chapter on visual ethnography in education that refers to photography and covers such aspects as 'participatory photography' and 'photo-elicitation' interviews as well as the challenges of getting access to research sites due to institutional review boards (Holm, 2018). However, while compiling this research review, what became clear was that, although photography as a research method is quite common within the early years of education, as well as in community (non-school) settings and other anthropological or sociological research (Barker and Smith, 2012), it appears to be used less often with learners within compulsory education. Returning to Kaplan et al., they noted this in their work over a decade ago (2007) but it could be argued that the field has not expanded significantly since then. This is despite the fact that the method is clearly and continually being developed in other fields, while appreciation and understanding of visual culture grows. This is a curious point that will be explored more fully in the concluding section of this article, where ethical concerns and understandings of children will feature.

\section{Scope of this Review and Search Strategy}

This research review is a qualitative, narrative review (Efrat et al., 2019) focused solely on the use of photography as a research method with learners in compulsory education. This type of review aims to 'survey the state of knowledge in a particular subject area and offers a comprehensive background for understanding that topic.' (p. 21) It is based on articles in English language journals that report empirical research as this is the only language in which I am fluent. Therefore, it is unsurprising that many of the articles have been written by English native speakers in English-speaking countries.

In terms of search strategy, I followed Reed's stages (2017). I did an initial general search based on Google and Google Scholar, looking for 'photography as research method' to check on terminology. After reading generally about 
visual and photographic methods, I then turned to academic databases, beginning with Scopus. I did a Boolean search of titles, key words and abstracts, with my search terms refined to 'photography', 'education'/'school'/'learning' and 'research' and 'method'. I limited the disciplines to 'arts and humanities' and 'social sciences.' I also limited the search to research articles and excluded books and book chapters. I did not limit the time period at this stage, although I was aware from my initial reading that very little was available from before the early 2000s. I also did not limit the country focus. This brought up 135 research articles. I also used the references in the selected relevant papers that were more broadly on 'children' and 'photography' to plug gaps, particularly of papers that did not appear on Scopus. Some of these used the term 'participant photography' or 'photovoice' or 'visual' or 'arts-based'. Finally, I searched the Taylor and Francis journal website to fill in any remaining gaps. After a brief review of titles and abstracts, I excluded papers that did not relate to compulsory education (a significant number). Once I had briefly scanned these articles, I also excluded those that did not focus on the use of the method with learners specifically.

In total the review is based on 31 articles that report empirical research studies. The findings focus on key themes that emerge from this research review. The list of papers included in this review can be found in Table 1 and in list form at the end of this article.

\section{Research Review Themes}

While all of the thirty-one articles reviewed for this paper focused on learners in compulsory education, they covered a wide range of topics within education in a variety of countries. These included gender and bullying in schools in England (Newman et al., 2006), inclusion of learners with special educational needs and disabilities in UK, Zambia and Indonesia (Kaplan et al., 2007), the school experiences of Black middle-class male youth in high school in USA (Allen, 2012), the views of learners in Nordic countries on healthy and unhealthy eating (Berggren et al., 2017), transition of learners from primary to secondary schools in Bangladesh (Shohel, 2012), the understandings of inclusion held by migrant learners in schools in England (Hanna, 2018) and friendship and meaning in young people's lives in Australia (O'Rourke et al., 2019). The themes explored are necessarily selective and not intended to be exhaustive. However, this thematic section is offered as a summary of some of the key focal points, highlighting significant diversities and commonalities, and with these, some gaps and critical questions that will be discussed and suggested to be taken 


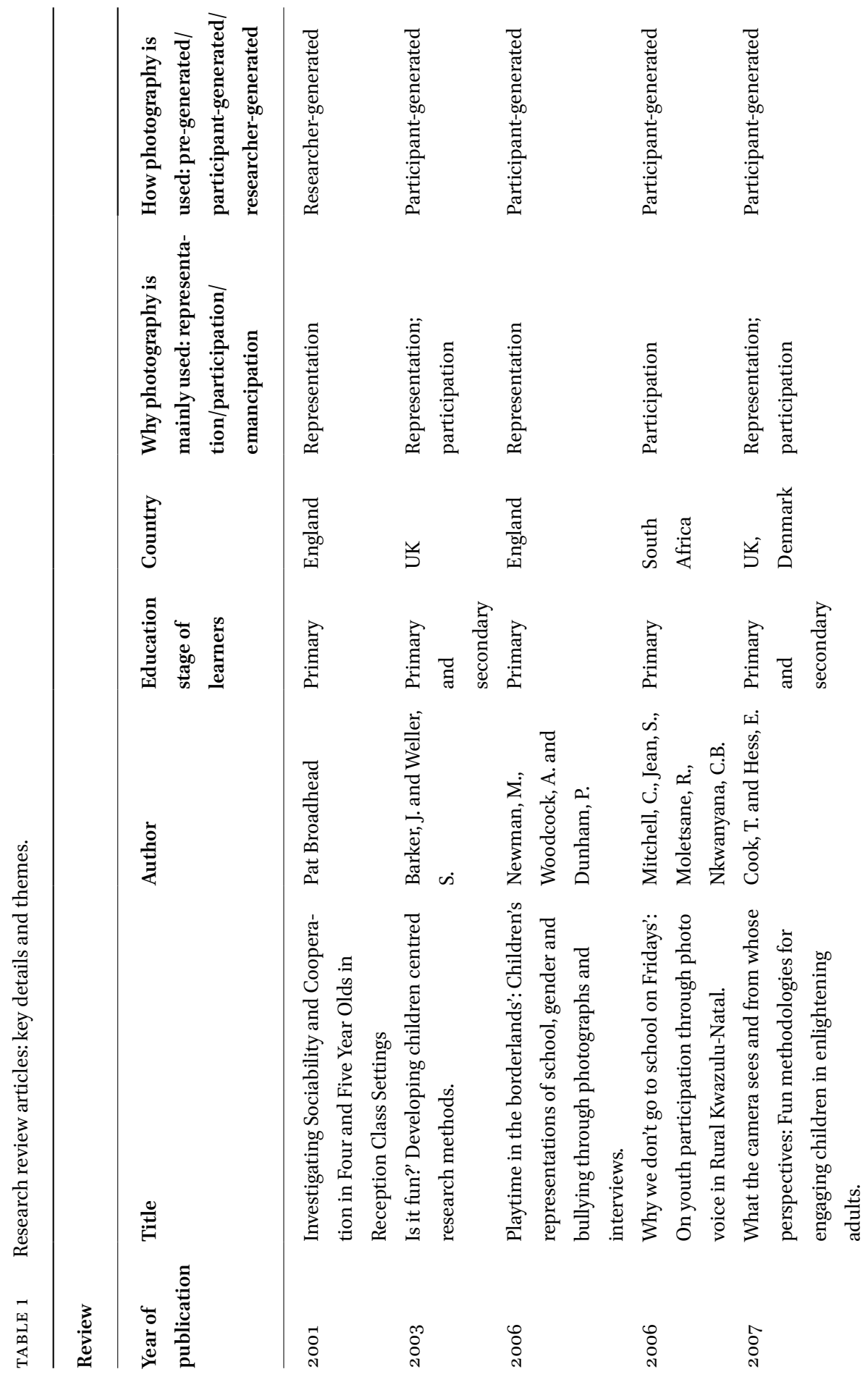




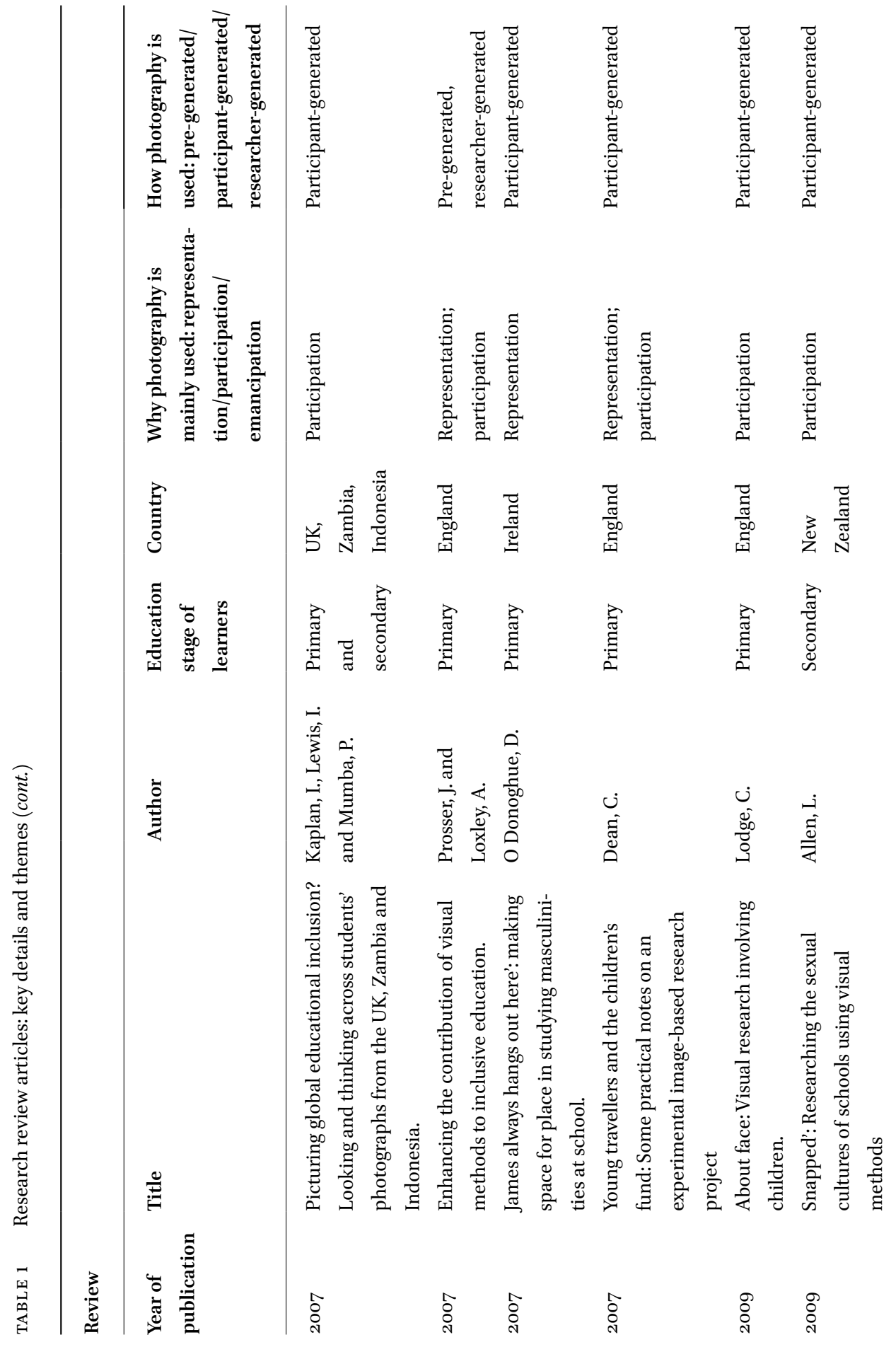



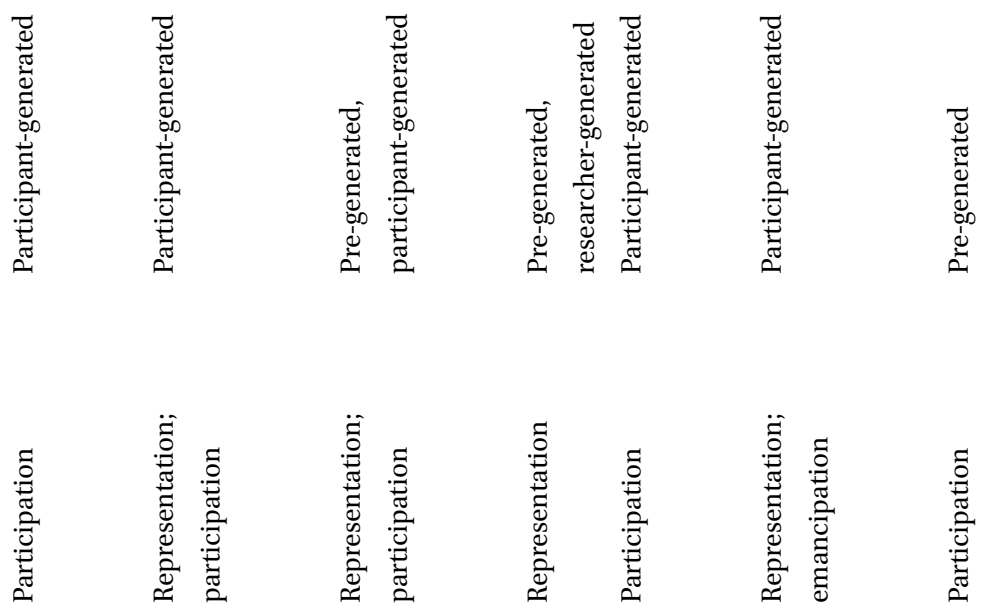

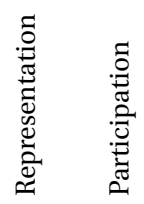

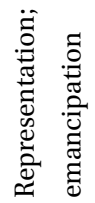

:

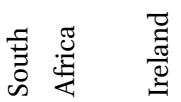

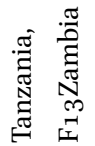

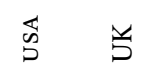

岕

$\frac{\frac{\pi}{0}}{\frac{\pi}{0}}$

芑芑

苞

胥

预

胥

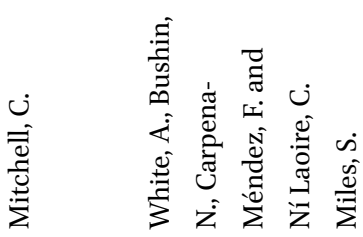

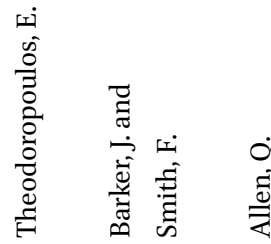

نं
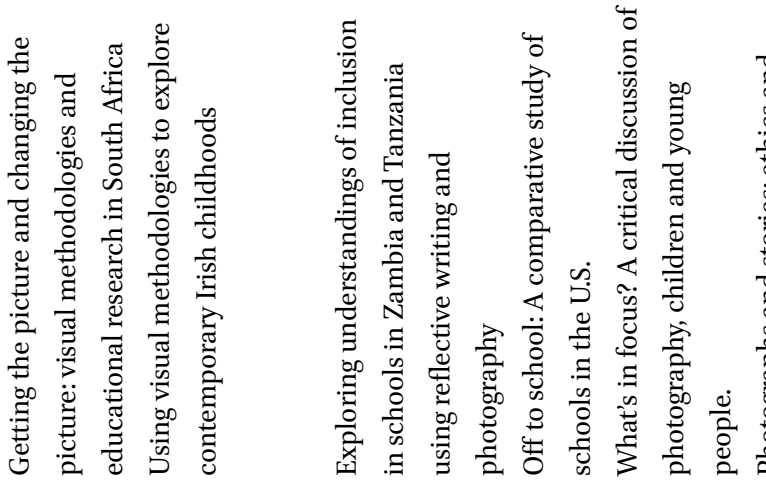

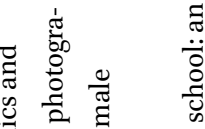

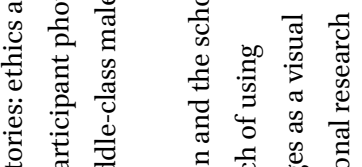

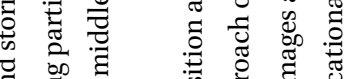

:

完

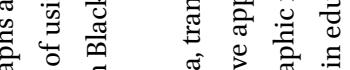
ก
ค
$\stackrel{\text { กิ }}{\stackrel{5}{0}}$
స్

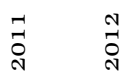
$\frac{4}{3}$
กั 


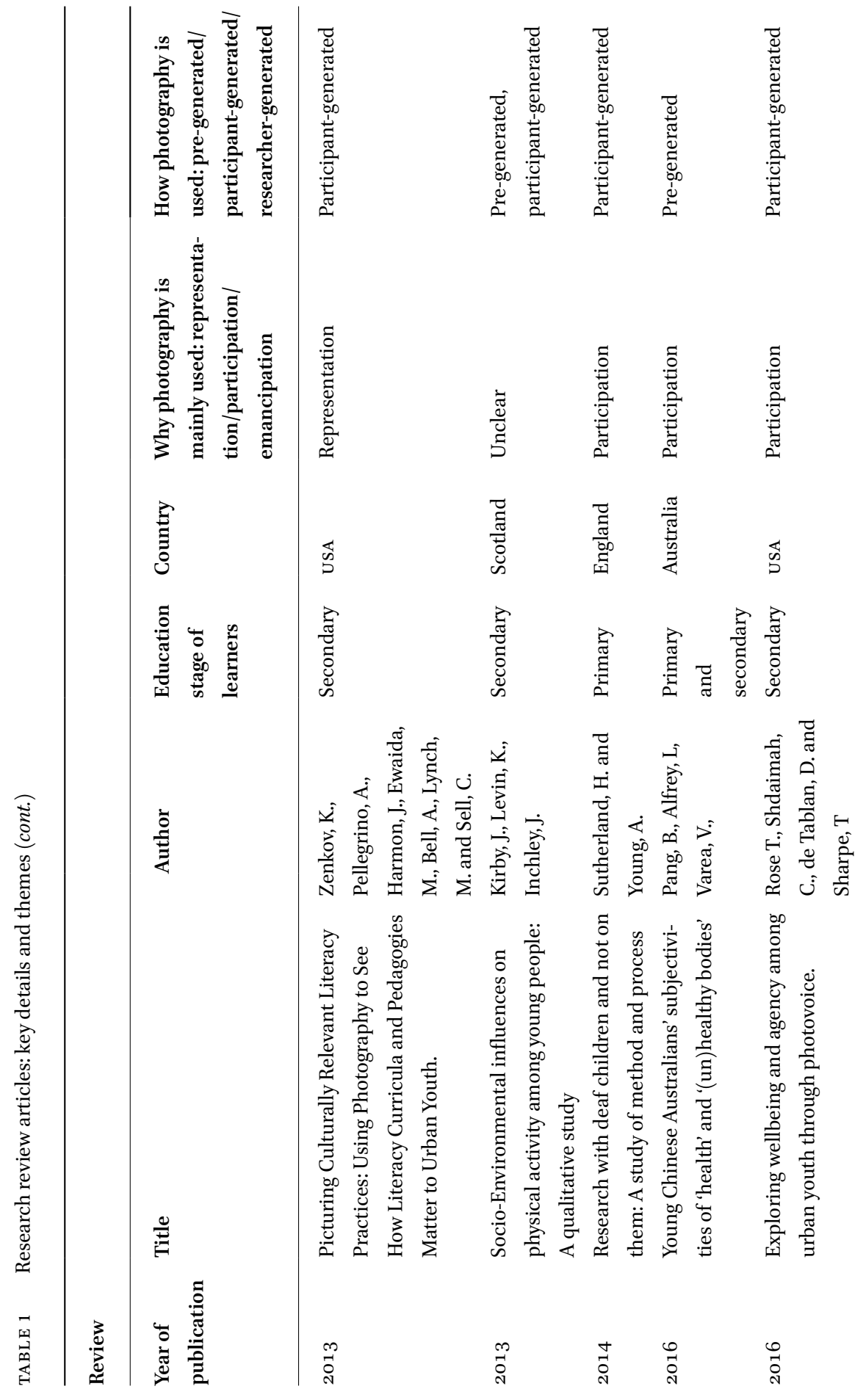



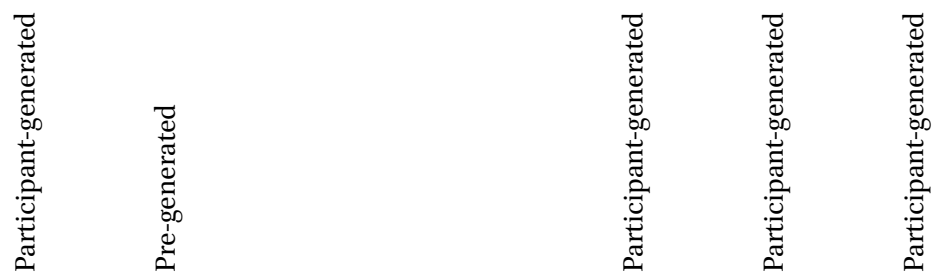

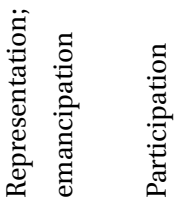
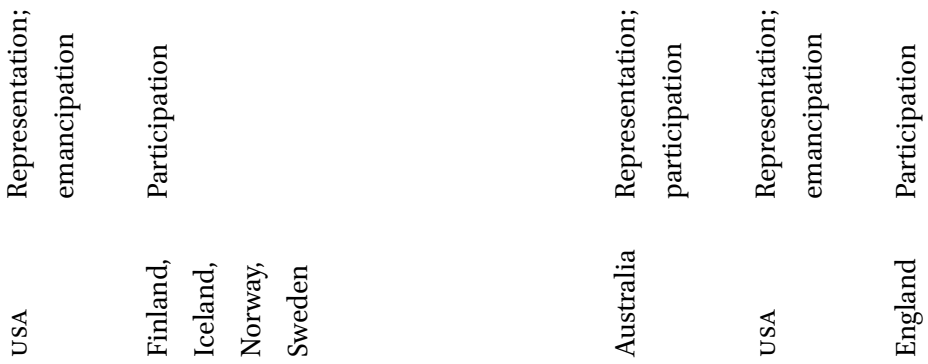

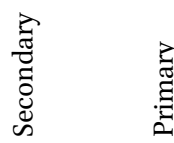

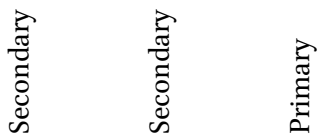

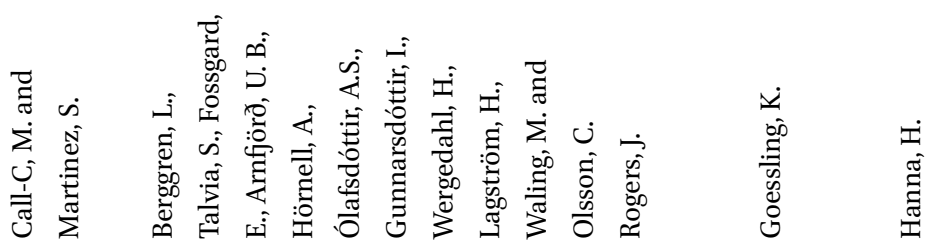
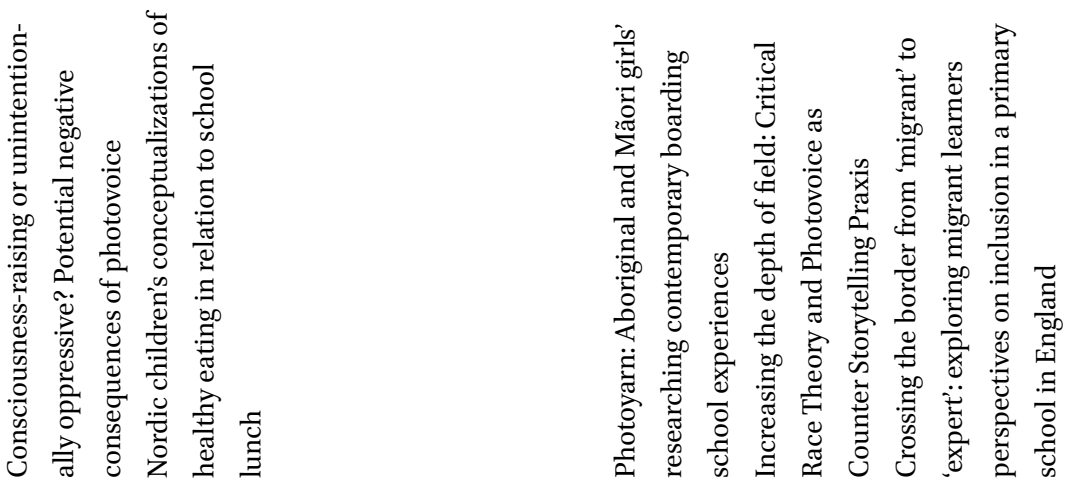

\begin{tabular}{ll}
$n$ & \multicolumn{1}{c}{} \\
0 & 0 \\
0 & 0
\end{tabular}

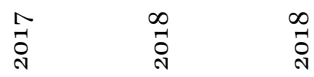




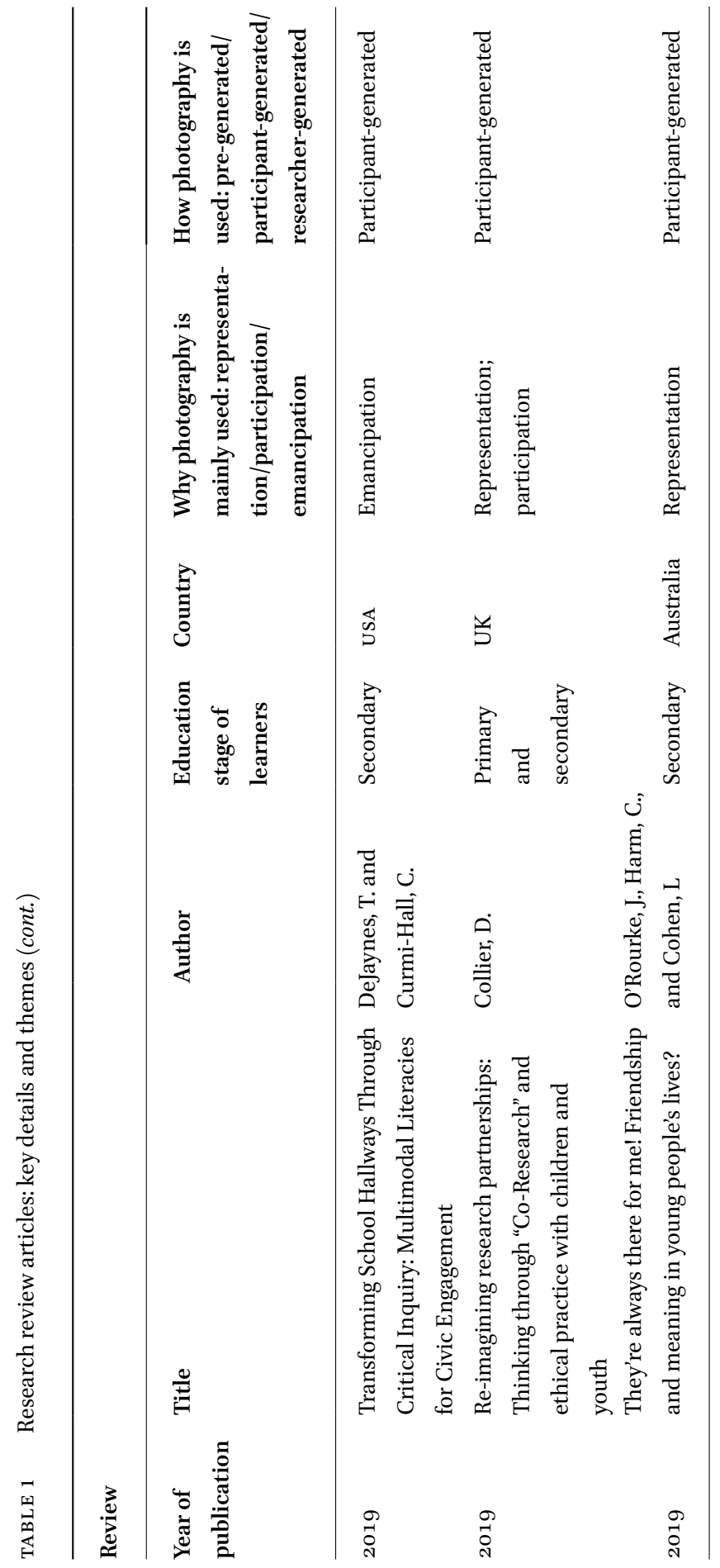


forward in future research. The two themes are: why photography is used; and how photography and photographs are used. Each of these themes will be treated individually below. Key points from the themes are noted in table 1.

\subsection{Why Photography is Used: Representation, Participation and Emancipation}

As referred to earlier, Kara (2015) has stated that research methods in social research should be 'fit for purpose'. This means that a researcher should think carefully about what method would best fit the research topic and the research participants with whom they wish to engage.

It appears that the photographic method is viewed within the selected articles as appropriate for use with a range of different learners in education, and this raises a question about motivation in choosing this method from the vast array of options that are available to any researcher. Despite some critical discussion of the use of the photographic method, most authors were drawn to this approach as an alternative to traditional qualitative methods that focus on the spoken word or observable phenomena, due to its potential to uncover issues that are not often explored, with groups who aren't often asked, thus adding a richness that may otherwise be absent. Subsequently, three dominant and, in some cases, interlinked terms that emerged were 'representation', 'participation' and 'emancipation'. In many cases the researchers discussed more than one of these terms as the focus of the research.

A number of the papers stated that they used photographic methods in order to better 'represent' the views or experiences of a particular group of research participants. These were often used in conjunction with other methods, such as in Rogers' (2017) study with teenage female Aboriginal and Maori learners in Australia and New Zealand, that innovated to create the method of 'photoyarn' that combined photography with indigenous yarning and yarning circles to represent these students' experiences. Barker and Weller's (2003) study on spatial mobility of learners viewed representation of children's 'real' experiences as key, as did Dean's (2007) work with Traveller children and Cook and Hess's (2007) research with learners with special educational needs and disabilities. Allen's (2009) study on sexual cultures within secondary schools viewed photography as offering participants 'alternative means of recounting their stories' (p. 550). Taking representation further, Collier's (2019) work with children (as part of families) wished to 'disrupt normative representations of families' (p. 48). Therefore it was not just about offering a standardized representation of experience, but also challenging current or common representations. Nevertheless, the question remains, and is often raised by these and other authors, about the extent to which a photograph can be described as 
truly representative of a person, place, time or concept. Reflecting the background debates of many of the studies included in this review, Newman et al., (2006) describe representation as a debate between 'realist' and 'critical' approaches, between the idea that a photograph can be accurately representative, and the idea that any image invites interpretation and a construction of meaning among a number of actors. There are also significant issues of power, given that it is normally the adult researchers who ultimately get to decide what gets shared from the research work with learners (Cook \& Hess, 2007). In this way, it is a deeply ethical issue and researchers need to very carefully consider whether what they are offering is a representation that is in line with what the photographer and/or the photographed intended, in addition to be cognizant of the fact that what the image represents may be viewed differently by the audience (particularly salient in projects where the images are displayed, such as Goessling, 2018) and also that this may change over time.

A large number of papers foregrounded the 'participatory' side of the photography, where it was chosen in order to promote participation and 'voice' in educational research on a particular topic. In Prosser and Loxley's (2007) paper that focused on the inclusion of learners with special educational needs in education and research, they describe visual methods as appropriate to their study as they 'gave 'voice' and agency to those less able in number, language and textual skills which have systematically biased accounts in past qualitative research.' (p. 59) Lodge's (2009) work on understandings of learning stated their view that photography 'offers a very accessible way for young people to become active in the research process themselves, to reverse the normal role of having research done to them, and allow them to participate more in this process' (p. 366). Similarly, Hanna (2018) used photography as a way of promoting participation of migrant learners, some non-native speakers of English, in research, due to the lack of competence in English language required to engage with visual methods. Mitchell (2008), in her extensive research in South Africa, suggested that using such methods forms part of a researcher's social responsibility to encourage participation in educational research of a variety of groups. Several studies went further to suggest that photographic methods were specifically child-friendly (e.g., Berggren et al., 2017; Sutherland \& Young, 2014; Cook \& Hess, 2007). However, a question does arise as to the particular ways in which participants might be participating or not participating - such as whether lack of enthusiasm for taking photographs might represent a withdrawal of consent (Barker \& Smith, 2012) - as well as whether that creates a false sense of agency to effect change (Allen, 2009). Furthermore, it must not be assumed that photography is automatically a more 'child-friendly' method than any other; returning to Kara (2015), all methods should be 'fit for purpose' and adapted to the particular context of the research. 
Finally, another tranche of papers in this review focused more on the 'emancipatory' potential of using photography as a method in educational research. DeJaynes and Curmi-Hall (2019) used photography to highlight the lack of representation for women of colour in the media, and thereby 'provoked critical conversations about race and gender in their school community.' (p. 299) CallCummings and Martinez (2016) viewed photography by Latino/a youth on challenging racism in schools as a way of 'unsilencing' them, allowing their voices to be heard as a way of empowering them. Goessling (2018) used the term 'counter storytelling' (Stovall, 2006) to describe how she viewed photography, offering young people of color in USA high schools the chance to counter the dominant narratives about their lives, through not only taking but also displaying their photos. Allen (2012) stated that Black male youth participants in his study 'expressed excitement over getting to share their stories and were hopeful that schoolteachers and administrators would understand them better.' (p. 452) It is interesting to note that the distinctly emancipatory tone appears to come out most strongly from studies based in the USA where the research participants were secondary school age. This raises questions about whether the perception of agency is absent in many other countries, particularly among primary-age learners, perhaps showing that in compulsory education there remains the sense, introduced earlier, that younger learners are 'human becomings' in need of development and adult protection rather than fully-fledged 'human beings' with valid opinions and agency (James \& James, 2004).

In addition to the motivation behind using photography, another key theme was how photography and the photographs themselves were used. This is the second theme and is considered below.

\subsection{How Photography and Photographs are Used:Pre-generated, Researcher-generated and Participant-generated Photographs}

Many of the studies in this review paid tribute to the development of specific sub-methods within photography-as-method, such as 'photo-voice' (Wang \& Burris, 1997) and 'photo-elicitation' (Collier \& Collier, 1986). However, even where these tried-and-tested methods were employed, researchers used photography and photographs in a variety of ways. There was a clear distinction between those studies that used 'found' or pre-generated photographs and those where the participants generated the photographs themselves.

There were only a small number of papers that used pre-generated and/ or researcher-generated photographs. These were normally shown to the participants as a way of prompting discussion. Berggren et al.'s (2017) study on learners' perceptions of un/healthy food used pre-generated photographs that were shared with focus groups of children who looked at and then discussed 
them. Pang et al.'s, (2016) research on subjectivities of un/healthy bodies among Chinese Australian youth used photographs of different bodies from magazines to elicit their views. In part of Miles' (2011) study, researchergenerated photographs of one school (in Zambia) were shown to learners in another school (in Tanzania) to prompt discussion. Shohel's (2012) study on primary-secondary transition for learners in Bangladesh (2012) used researchergenerated photographs of the learners' primary school to bring back memories for the learners. Unusually for the selected studies, two papers described researcher-generated photography: Theodoropoulos (2011) uses the photographs taken by herself of a school, and then analyses them herself to explore the school experiences of learners in socioeconomically divergent schools; and Broadhead (2001) uses researcher-generated photographs of shifts in stages of play among young primary school learners. While such studies may raise questions about representation and interpretation (see Rose, 2011), the apparent effectiveness that authors report does pose a challenge to the popular idea that photographs must be generated by participants in order to promote participation in research. It may be that pre-generated photographs are more suitable than participant-generated photographs for exploring particular topics, especially where the issues might be deemed too sensitive to warrant the production of photographs that might be attributed to particular individuals. Indeed, confidentiality is another ethical concern that was mentioned frequently in the articles under review (see, for example, Mitchell et al., 2006).

Much more popular than the use of pre-generated photographs was the approach whereby research participants themselves generated photographs. Unsurprisingly, this appears to overlap with studies that saw themselves as overtly 'representative', 'participatory' or 'emancipatory'. Many of these studies stated that photo-voice was used, such as Mitchell et al.,'s (2006) work on school absenteeism in rural South Africa, Call-Cummings and Martinez's (2016) study with Latino/a youth in USA, Zenkov et al.'s (2013) research on literacy with high school students in U SA, and Rose et al.'s (2016) study on wellbeing among adolescents in USA. Usually, research participants were provided with a disposable (e.g. Barker \& Smith, 2012) or digital camera (e.g. Lodge, 2009) and were given the task of taking photographs relating to a particular topic, either within school, with the researcher being present (e.g., Hanna, 2018) or outside school, independently and without the researcher being present (e.g. White et al., 2010). Then these cameras were returned to the researcher and at least some of the photographs were developed/printed for the participants to view. The majority of studies that involved participants taking photographs themselves used a version of 'photo-elicitation' following the photograph-taking in order to find out participants' meanings and intentions in taking the photographs, and/or to promote discussion or debate on a 
particular topic. In O'Donaghue's (2007) study on gender and masculinities in Irish primary schools, participants added written captions to their images, based also on notes that they had taken down as they took their photographs. Barker and Smith's (2012) paper describes two different approaches: one where a written inscription was added to the photos and another where the photographs were used as a stimulus for oral discussion during individual interviews rather than pinpointing a caption. In their study on deaf children's experiences of school, Sutherland and Young (2014) used computers to allow participants to edit the images and to add their own interpretations to them. In these kinds of studies, then, the issue of representation and interpretation again came to the fore, with many selecting photo-elicitation as a way of trying to foreground the interpretations of learners rather than those of the adult researchers.

It is worth adding that a small number of studies combined the use of pregenerated and participant-generated photographs. For example, Kirby, Levin and Inchley (2013) investigated the environmental factors that influence physical activity participation among young people in Scotland, where primary school participants created blogs using some of their own and 'found' images as a way of capturing the full extent of what they wanted to say, or to keep their own images private. It may be that this offers a more inclusive approach as learner-participants have the choice of creating or finding images that satisfy them, rather than experiencing discomfort in viewing their own 'inadequate' photographs or sharing their own images without fully informed consent. Indeed, given that most studies stated that their aim was to be inclusive, then this approach may go some way towards achieving this.

Springing from this, then, is the issue of involvement of research participants in data analysis or in 'member checking' once the findings have been drafted. As with the issue of representation, this is an ethical issue, thus showing how ethical dilemmas are threaded through the entire research process, and pertinent often long after the formal research period has come to an end. While it may be argued that photo elicitation goes some way towards involving participants in data analysis, the reality remains that the opportunity to return to the schools and learners and get their input into the analysis of the data was rarely offered or taken (with the exception of Sutherland and Young's (2014) computer-based analysis with deaf children). The child rights-based approach developed most extensively by Laura Lundy (see Lundy, 2007) would argue that children should be involved at every stage of research, including design, fieldwork, data analysis and dissemination, and so this last stage would be invaluable.

However, it may be argued that the sharing of these photographs (often with captions) is another way of involving participants in data analysis, given that they have some control over what gets shared. This was the case in a number 
of the studies, where a school- or community-based exhibition was set up (e.g., DeJaynes \& Curmi-Hall, 2019; Rogers, 2017; Rose et al., 2016; Call-Cummings \& Martinez, 2016; Kaplan et al., 2007; Mitchell et al., 2006). Nevertheless, it remains the case that the audience has the freedom to interpret the images on display in their own way, which may be entirely different from the intentions of the learner-photographers, and therefore may not promote the kind of 'counter storytelling' that scholars such as Goessling (2018) or Allen (2009) might wish for.

Summary and Reflecting on the Prospects for Photography as a Research Method in Education

This article reviewed 31 research articles from 2001-2019 on the use of photography as a research method with learners in compulsory education. It was set against the background of discussions around 'visual', 'participatory' and 'artsbased' research methods, and the growth of photography as a method in general was attributed to shifts in understandings of children and young people that came around the time of the adoption by the UN of the United Nations Convention on the Rights of the Child in 1989, and the movement within the sociology of childhood that began to more vocally advocate the appreciation of different, agentic childhoods and children. It was highlighted that while photography is popular in some disciplines, it remains a relatively underutilised research method with learners in school-based compulsory education. Nevertheless, 31 research articles were selected for the qualitative, narrative review, and two themes were drawn out. The first theme related to the motivation behind the authors' use of photography as a research method. Motivations were classified in three ways: representation, participation and emancipation. While the analysis broadly agreed that these were laudable aims, it also raised issues relating to the extent to which a photograph can represent reality and the issue of interpretation by the photographer, the photographed, and the audience, as well as whether participation always indicates consent and whether participation in research can create a false sense of agency to effect change. Another point that was considered was that it appeared to be the studies based in secondary education in the USA that had an overtly emancipatory agenda, and reflected on whether this indicated that, in other countries and in primary education, there is still the sense that learners cannot effect real change.

The second theme considered how photography and the photographs themselves were used in the studies related in these articles. This was broadly divided into two aspects: the use of pre-generated (or 'found') photographs; 
and the use of participant-generated photographs. While a small number of studies used pre-generated photographs, the overwhelming majority involved participants in generating and sometimes editing photographs, and further sometimes selecting photographs for dissemination. This led to a discussion around involving participants in the interpretation of the photographs, where 'photo-voice' and 'photo-elicitation' techniques were found to be very popular. It was found that only very few studies managed to return to the participants at a later stage for a final 'member-check' on the analysis, which for some authors was regrettable, and perhaps not fully in line with the 'child rights-based approach' to research.

Given the relatively small uptake of the photographic research method for use with learners in compulsory education (considering both the articles contained in this review as well as a number of monographs and edited volumes mentioned earlier), it is worth pondering, for a moment, why that is. Its limited use may come as a surprise, given that it feels like we are surrounded (bombarded?) by visual culture on a constant basis in the 21st century. This is not least because of the rapid rise and now pervasiveness of social media, particularly among young people (Woodfield, 2014). As Lodge (2009, p. 361) notes, there are 'contradictions between the current widespread practice of visual recordings in public and private spheres and the cautious approach adopted in educational research'. This is a conundrum that this Special Issue on 'Visual Methods in Educational Research' seeks, in part, to address, and I would like to make my contribution here too.

One of the biggest concerns that has emerged with the rise of photographic research methods is that of ethics, and certainly ethical concerns were something that many of the authors of the articles in this review very clearly grappled with. It appears to be a particularly thorny issue due to the (perceived or real) higher chance of participants being identified through images of their faces than via text-based methods. There are also ethical considerations around the potential for mis-representation of participants' images (as mentioned above by Rose, 2001), whether children and young people, unfamiliar with research and researchers, can be said to have given 'fully informed consent' and who, ultimately, owns the images. These are challenges over which researchers are not agreed, and different researchers have chosen to use the images in different ways, with some using them in public displays, some using software to turn photographs into cartoons or line drawings, others blurring faces in published work, and still others publishing or even holding on to no images at all. In addition to ethical concerns, allusion was made earlier to understandings of children and young people as 'human becomings' rather than 'human beings' as it was noted that there has been some shifting in this area, not least thanks to the UNCRC 1989. However, it may be that the idea of young 
people as 'human becomings' still prevails and may go some way towards explaining the low uptake of the photographic method in the school environment. While full exploration of these issues is beyond the scope of this study (see Thomson, 2008, for a good summary), it is important to be aware that the rise of university ethics committees and schools' increasing concerns about being legally challenged over misuse of images, juxtaposed with the everincreasing popularity of image-based social media, mean that this debate is likely to continue to evolve. (Wang \& Redwood-Jones, 2001; Mitchell, 2016)

However, I would like to posit that it is not only such important ethical and age-related concerns that may be contributing to the lack of use of photography in school-based research; it may also be that access to schools is restricted as research using photography is not strictly related to the 'core' subjects of literacy or numeracy. Therefore, it is a challenge for researchers to convince schools of the benefits of their research and may explain why so many of the studies included in this review were very clear about their intentions in using photography and photographs: many of them had to engage in a process of negotiation with schools in order to gain access (Allen, 2009, is a case in point). This is certainly a challenge that I, as a user of photographic research methods, have faced (see Hanna, 2018).

A final conundrum that arises from this research review is the fact that the photographic research method is not widely used in compulsory education outside the 'West'. This is of particular significance to a journal like this one the Beijing International Review of Education - as there is so little published work on the use of photography as a research method in education in China in English or, I am reliably informed by my local colleagues, in Chinese. The USA and UK show most often in searches for research papers. It would be useful for future research to consider more extensively why that might be, so that all methods might be considered, and so that we can all work towards using methods that are 'fit for purpose' and inclusive of all groups in education.

To close, it is important to return to the motivation behind using photography, and why at least some researchers continue to forge ahead in developing the method. I am convinced that photography can be a useful research method in education as long as one remembers that it is imperfect and partial, and should be understood within and adapted to a context, where the researcher is always ready to abandon the method if it is not effective or appropriate. It can contribute to answering some of the most important questions within education, but it cannot answer any one question in full. The final word is left for the author of one of the articles in this review:

How can research located in, and mediated through, the school do other than reproduce existing power relationships, or invite the young people 
to collude in them? Unless the young people themselves are active in the research processes - for example helping to create and to derive meaning from images - then the tendency for adults to create their own answers will endure. (Lodge, 2009, p. 366)

As I have written elsewhere (Hanna, 2019) as have many others, this need to reflect the narratives of those within the education systems that we, as social researchers, hope to benefit, continues to be a moral imperative and one that requires our continual engagement.

\section{References}

Alderson, P., \& Morrow, V. (2004). Ethics, social research and consulting with children and young people. Barnardo's.

Banks, M. (2001). Visual Methods in Social Research. Sage.

Chevalier, J.M., \& Buckles, D.J. (2013). Participatory Action Research: Theory and Methods for Engaged Inquiry. Routledge.

Collier, J., \& Collier, M. (1967). Visual Anthropology: Photography as a Research Method. University of New Mexico Press.

Efrat Efron, S., \& Ravid, R. (2019). Writing the Literature Review. The Guilford Press.

Hanna, H. (2019). Children's Right to Participation and Consultation: Involving them in creative visual research. In C. Capewell and A. Fox, How inclusive of children are our educational research methods?, Research Intelligence, Issue 39, Summer 2019 (pp. 29-30). BERA. Available at: https://www.bera.ac.uk/researchers-resources/ publications/summer-2019.

Harper, D. (2002). Talking about pictures: A case for photo elicitation. Visual Studies $17(1), 13-26$.

Holm, G. (2018). Visual ethnography in education. In D. Beach, C. Bagley and S. Marques da Silva (Eds.), The Wiley Handbook of Ethnography in Education (pp. 325-354). Wiley.

James, A. and James, A. (2004). Constructing Childhood: Theory, Policy and Social Practice. Palgrave Macmillan.

Kara, H. (2015). Creative Research Methods in the Social Sciences. Policy Press.

Knowles, J. G., \& Cole, A. L. (Eds.). (2008). Handbook of the Arts in Qualitative Research: Perspectives, Methodologies, Examples and Issues. SAGE.

Lansdowne, G. (2011). Every child's right to be heard: A resource guide on the UN Committee on the Rights of the Child General Comment no.12. Save the Children Fund/UNICEF.

Leavy, P. (2008). Method Meets Art: Arts-Based Research Practice. Guilford Publications. 
Lundy, L. (2007). 'Voice' is Not Enough: Conceptualising Article 12 of the United Nations Convention on the Rights of the Child. British Educational Research Journal, 33(6), 927-942.

Miles, S., \& Howes, A. (Eds.). (2015). Photography in Educational Research: Critical Reflections from Diverse Contexts. Routledge.

Mitchell, C. (2016). Doing Visual Research. SAGE.

Pink, S. (2001). Doing Visual Ethnography. SAGE.

Piper, H., \& Frankham, J. (2007). Seeing voices and hearing pictures: Image as discourse and the framing of image-based research. Discourse: Studies in the Cultural Politics of Education, 28(3), 373-387.

Prosser, J. (1998). The status of image-based research. In J. Prosser (Ed.), Imagebased Research: A Sourcebook for Qualitative Researchers. (pp. 97-112) Routledge Falmer.

Prout, A. (2001). Representing children: reflections on the children $5^{-16}$ programme, Children and Society, 15, 193-201.

Reason, P., \& Bradbury, H. (Eds). (2008). The Sage Handbook of Action Research: Participative Inquiry and Practice. SAG E.

Reed, M. (2017). The Productive Researcher. Fast Track Impact.

Rose, G. (2001). Visual Methodologies: An Introduction to Researching with Visual Materials. SAGE.

Stirling, E., \& Yamada-Rice, D. (Eds.). (2015). Visual Methods with Children and Young People: Academics and Visual Industries in Dialogue. Palgrave Macmillan.

Thomson, P. (Ed.). (2008). Doing Visual Research with Children and Young People. Routledge.

Wang, C. (1999). Photovoice: A participatory action research strategy applied to women's health. Journal of Women's Health, 8(2), 185-192.

Wang, C., \& Redwood-Jones Y. (2001). Photovoice ethics: perspectives from flint photovoice. Health Education \& Behavior 28, 560-572.

Wetton, N.N., \& McWhirter, J. (1998). Images and curriculum development in health education, in J. Prosser (Ed.), Image-based Research (pp. 263-283). Falmer Press.

Woodfield, K. (2014). Social Media in Social Research: Blogs on Blurring the Boundaries. NatCen Social Research.

\section{Review Articles}

Allen, L. (2009). 'Snapped': researching the sexual cultures of schools. using visual methods. International Journal of Qualitative Studies in Education, 22(5), 549-561.

Allen, Q. (2012). Photographs and stories: ethics, benefits and dilemmas of using participant photography with Black middle-class male youth. Qualitative Research, $12(4), 443-45^{8}$. 
Barker, J., \& Weller, S. (2003). “Is it Fun?” Developing Children Centred Research Methods. International Journal of Sociology and Social Policy, 23(1/2), 33-58.

Barker, J., \& Smith, F. (2012). What's in focus? A critical discussion of photography, children and young people. International Journal of Social Research Methodology, 15(2), 91-103.

Berggren, L., Talvia, S., Fossgard, E., Arnförð, U. B., Hörnell, A., Ólafsdóttir, A.S., Gunnarsdóttir, I., Wergedahl, H., Lagström, H., Waling, M., \& Olsson, C. (2017). Nordic children's conceptualizations of healthy eating in relation to school lunch. Health Education, 117(2), 130-147.

Broadhead, P. (2001). Investigating Sociability and Cooperation in Four and Five Year Olds in Reception Class Settings, International Journal of Early Years Education, 9(1), 23-35.

Call-Cummings, M., \& Martinez, S. (2016). Consciousness-raising or unintentionally oppressive? Potential negative consequences of photovoice. The Qualitative Report, 21(5), 798-810.

Collier, D. (2019). Re-imagining research partnerships: Thinking through "co-research" and ethical practice with children and youth. Studies in Social Justice, 13(1), 40-58.

Cook, T., \& Hess, E. (2007). What the camera sees and from whose perspective: Fun methodologies for engaging children in enlightening adults. Childhood, 14(1), 29-45.

Dean, C. (2007). Young Travellers and the children's fund: Some practical notes on an experimental image-based research project. Journal of Research in Special Educational Needs, 7(1), 16-22.

DeJaynes, T., \& Curmi-Hall, C. (2019). Transforming School Hallways Through Critical Inquiry: Multimodal Literacies for Civic Engagement. Journal of Adolescent \& Adult Literacy, 63(3), 299-309.

Goessling, K. (2018). Increasing the Depth of Field: Critical Race Theory and Photovoice as Counter Storytelling Praxis. Urban Review, 50, 648-674.

Hanna, H. (2018). 'Migrant learners as experts: Exploring their perspectives on inclusion in a primary school in England'. Children's Geographies. https://doi.org/10.1080 /14733285.2018.1548693.

Kaplan, I., Lewis, I., \& Mumba, P. (2007). Picturing global educational inclusion? Looking and thinking across students' photographs from the UK, Zambia and Indonesia. Journal of Research in Special Educational Needs, 7(1), 23-35.

Kirby, J., Levin, K., \& Inchley, J. (2013). Socio-Environmental influences on physical activity among young people: A qualitative study. Heath Education Research, 28(6), 954-969.

Lodge, C. (2009). About face: visual research involving children, Education 3-13, 37(4), 361-370. 
Miles, S. (2011). A understanding of a case study: Analysis of a robust qualitative research methodology. International Journal inclusion Inclusive Education, 17(3), $310-328$.

Mitchell, C. (2008). Getting the picture and changing the picture: visual methodologies and educational research in South Africa. South African Journal of Education, 28, 365-383.

Mitchell, C., Stuart, J., Moletsane, R., \& Nkwanyana, C.B. (2006). Why We Don't Go to School on Fridays: On Youth Participation through Photo Voice in Rural KwaZuluNatal. McGill Journal of Education, 41(3), 267-282.

Newman, M., Woodcock, A., \& Dunham, P. (2006). 'Playtime in the Borderlands': Children's Representations of School, Gender and Bullying through Photographs and Interviews, Children's Geographies, 4(3), 289-302.

O Donoghue, D. (2007). 'James always hangs out here': making space for place in studying masculinities at school. Visual Studies, 22(1), 62-73.

O'Rourke, J., Harm, C., \& Cohen, L. (2019). They're always there for me! Friendship and meaning in young people's lives? Scandinavian Journal of Psychology, 6o, 596-6o8.

Pang, B., Alfrey, L., \& Varea, V. (2016). Young Chinese Australians' subjectivities of 'health' and '(un)healthy bodies'. Sport, Education and Society, 21(7), 1091-1108.

Prosser, J., \& Loxley, A. (2007). Enhancing the contribution of visual methods to inclusive education. Journal of Research in Special Educational Needs, 7(1), 55-68.

Rogers, J. (2017). Photoyarn: Aboriginal and Mãori girls' researching contemporary boarding school experiences. Australian Aboriginal Studies, 1, 3-13.

Rose T., Shdaimah, C., de Tablan, D., \& Sharpe, T. (2016). Exploring wellbeing and agency among urban youth through photovoice. Children and Youth Services Review, 67 , 114-122.

Shohel, M.M.C. (2012). Nostalgia, transition and the school: an innovative approach of using photographic images as a visual method in educational research. International Journal of Research \& Method in Education, 35(3), 269-292.

Sutherland, H., \& Young, A. (2014). Research with deaf children and not on them: A study of method and process. Children and Society, 28, 366-379.

Theodoropoulos, E. (2011). Off to school: A comparative study of schools in the U.S. CEPS, $1(2), 45^{-58}$.

White, A., Bushin, N., Carpena-Méndez, F., \& Ní Laoire, C. (2010). Using visual methodologies to explore contemporary Irish childhoods. Qualitative Research, 10(2), $143^{-158 .}$

Zenkov, K., Pellegrino, A., Harmon, J., Ewaida, M., Bell, A., Lynch, M., \& Sell, C. (2013). Picturing Culturally Relevant Literacy Practices: Using Photography to See How Literacy Curricula and Pedagogies Matter to Urban Youth. International Journal of Multicultural Education, 15(2), 1-20. 